\title{
ANALISIS STABILITAS LERENG AREA TIMBUNAN MENGGUNAKAN METODA KESETIMBANGAN BATAS PADA TAMBANG TERBUKA BATUBARA DAERAH PURWAJAYA, KECAMATAN LOA JANAN, KABUPATEN KUTAI KARTANEGARA
}

\section{SLOPE STABILITY ANALYSIS OF DISPOSAL AREA USING LIMIT EQUILIBRIUM METHOD AT OPEN PIT COALMINING, PURWAJAYA AREA, LOA JANAN DISTRICT, KUTAI KARTANEGARA REGENCY}

\author{
Tati Andriani ${ }^{1}$, Zufialdi Zakaria ${ }^{2}$, Dicky Muslim ${ }^{2}$, dan Agus Wiramsya Oscar ${ }^{2}$ \\ ${ }^{1}$ Fakultas Teknik Geologi, Universitas Padjadjaran, Sumedang \\ ${ }^{2}$ Pasca Sarjana Fakultas Teknik Geologi, Universitas Padjadjaran, Bandung \\ tatiandriani@gmail.com
}

\begin{abstract}
ABSTRAK
Salah satu prinsip pada penambangan terbuka (open pit mine) batubara adalah menggali tanah atau batuan penutup (overburden) untuk mendapatkan batubara, sehingga dibutuhkan tempat penimbunan untuk menampung overburden, yang disebut sebagai disposal area. Salah satu permasalahan pada disposal area adalah kondisi lereng yang tidak stabil sehingga terjadinya longsoran-longsoran yang dapat mengganggu jalannya operasi tambang seperti terhambatnya alat berat pengangkut material tambang. Agar disposal area tetap berada dalam kondisi stabil maka perlu adanya kajian geoteknik yang membahas mengenai kestabilan lereng, sehingga operasi tambang dapat berjalan dengan baik. Penelitian ini dilakukan untuk mengetahui kestabilan lereng disposal area pada tambang batubara di Purwajaya, Kecamatan Loa Janan, Kabupaten Kutai Kartanegara. Penelitian dilakukan dengan pengambilan data lapangan berupa geometri lereng serta karakteristik material pada disposal area. Kemudian dilakukan simulasi lereng untuk mendapat nilai FS (Safety-Factor) yang diperkirakan masih aman menggunakan metode kesetimbangan batas dengan bantuan aplikasi Slide Versi 6. Ketebalan timbunan saat ini sudah mencapai 20 meter, dengan sudut lereng keseluruhan adalah $9^{\circ}$. Hasil perhitungan nilai FS dari tiga sayatan menunjukkan, bahwa disposal area berada dalam kondisi belum aman dengan nilai FS pada setiap sayatan adalah 1,108; 1,21 dan 1,756. Parameter nilai FS yang dianggap aman adalah lebih besar dari 1,25. Untuk mendapatkan nilai FS optimum hasil dari simulasi untuk lereng keseluruhan, maka geometri lereng yang disarankan adalah tebal timbunan maksimum 20 meter dan sudut lereng optimal $9^{\circ}$, dengan dibuat undakan-undakan tinggi 7 meter dan sudut $30^{\circ}$ pada lereng. Hasil simulasi ini memiliki nilai FS 1,301 pada kondisi jenuh.
\end{abstract}

Kata kunci: Kestabilan lereng, disposal area, Purwajaya, Safety factor

\section{ABSTRACT}

One of the fundamental frameworks of open pit coal mining is carving out the overburden rock to reveal the coal bands, thus it needs a dumping area to dispose the overburden rocks. In disposal area, one of the problem is slope instability. It causes land failure and can endanger the workers and work flow in the mine area (e.g. hauling road can be blocked by falling material and cut the access of dumping truck loading the coal). Geotechnical approach will be needed to ensure the safety of mine area, no disruption in workflow and prevent such failure in the disposal's slope. This study aim to know slope stability of disposal area. The study conducted in a coalmine located at Purwajaya Area, Loa Janan District, Kutai Kartanegara Regency, East Kalimantan Province. The method used in this research consists of fieldwork and slope stability modeling. The thickness of overburden is 20 meter and the 
angle of overall slope is $9^{\circ}$. Value of Safety-factor (FS) from three section in disposal area indicates that the slope is unstable with FS in each section is 1.108, 1.21 and 1.756 respectively from section one to section three. FS parameter that reputed stable is over than 1.25. To find optimum FS value, simulations with software called Slide version 6 has been conducted. The result of FS value for 20 meters height slope with overall angle of $9^{\circ}$ is 1.301 . For single slope parameter, suggested bench height is 7 meters with an angle of $30^{\circ}$. Result of simulation has FS value of 1.301 in saturated condition.

Keywords: Slope stability, disposal area, Purwajaya, Safety factor

\section{PENDAHULUAN}

Salah satu sistem penambangan yang digunakan untuk mengeksploitasi sumberdaya alam seperti batubara adalah sistem penambangan terbuka, yang dimana segala aktivitas penambangannya dilakukan di atas atau relatif dekat dengan permukaan bumi. Prinsip pada penambangan terbuka (openpit mine) batubara adalah menggali tanah atau batuan penutup untuk mendapatkan batubara, tanah atau batuan penutup ini disebut sebagi overburden (Prasetyo, Hariyanto, \& Cahyadi, 2011). Dalam hal ini, tentunya dibutuhkan suatu area yang bisa dijadikan tempat untuk menimbun material buangan atau overburden ini. Area ini disebut sebagai disposal atau dumping area (Kristyanto, Muslim, \& Zakaria, 2015).

Dalam (Prasetyo et al, 2011) dijelaskan bahwa disposal area atau tempat penimbunan harus direncanakan dengan baik agar timbunan tanah tersebut berada dalam kondisi stabil. Salah satu yang perlu dianalisis mengenai disposal area adalah kajian mengenai kestabilan lereng. Kajian kestabilan lereng berhubungan dengan bagaimana geometri suatu lereng yang dapat dibentuk material tertentu agar menjadi stabil. Stabilitas lereng disposal tergantung pada faktor utama karakteristik material timbunan. Karakteristik material ini memuat perilaku material yang berbeda dengan perilaku batuan, sehingga stabilitas lereng disposal akan berbeda dengan stabilitas lereng batuan pada lokasi penambangan batubara. Kajian kestabilan lereng disposal area ini diperlukan untuk menghindari kelongsoran pada lereng sehingga operasi tambang dapat berjalan dengan baik (Behera, Kripamoy, Singh, Verma, \& Singh, 2016).

Sebaran batuan di daerah penelitian memiliki nilai jurus dan kemiringan perlapisan $\mathrm{N} 50^{\circ} \mathrm{E} / 15^{\circ}$. Lokasi disposal yang sedang berjalan hampir mencapai ketinggian maksimum yang direncanakan, sehingga diperlukan tempat lain untuk menampung overburden selanjutnya. Pemilihan area low wall sebagai tempat timbunan dikarenakan arena ini secara daya dukung mampu menahan beban timbunan hingga ketinggian material timbunan di area ini mencapai $100 \mathrm{~m}$, selain itu jaraknya yang cukup dekat dengan front, sehingga dapat mengefektifkan siklus waktu kerja. Dalam hal ini diperlukan kajian mengenai kestabilan leregnya, dalam arti meskipun area disposal mampu menahan beban tertentu, jika material timbunan itu sendiri tidak mampu bebannya, maka dapat terjadi lonsor.

Penelitian ini dilakukan di Desa Purwajaya, Kecamatan Loa Janan, Kabupaten Kutai Kartanegara dengan tujuan untuk mengetahui kestabilan lereng pada disposal area melalui simulasi lereng untuk mendapatkan nilai faktor keamanan optimum pada lereng disposal.

\section{TINJAUAN PUSTAKA Geologi Regional Daerah Penelitian}

Berdasarkan Peta Geologi Regional Lembar Samarinda (Supriatna, Sukardi, \& Rustandi, 1995) litologi daerah penelitian terdiri atas dua formasi penyusun dari tua ke muda yaitu Formasi Balikpapan (Tmbp) dan Formasi Kampungbaru (Tpkb) (Gambar 1). 


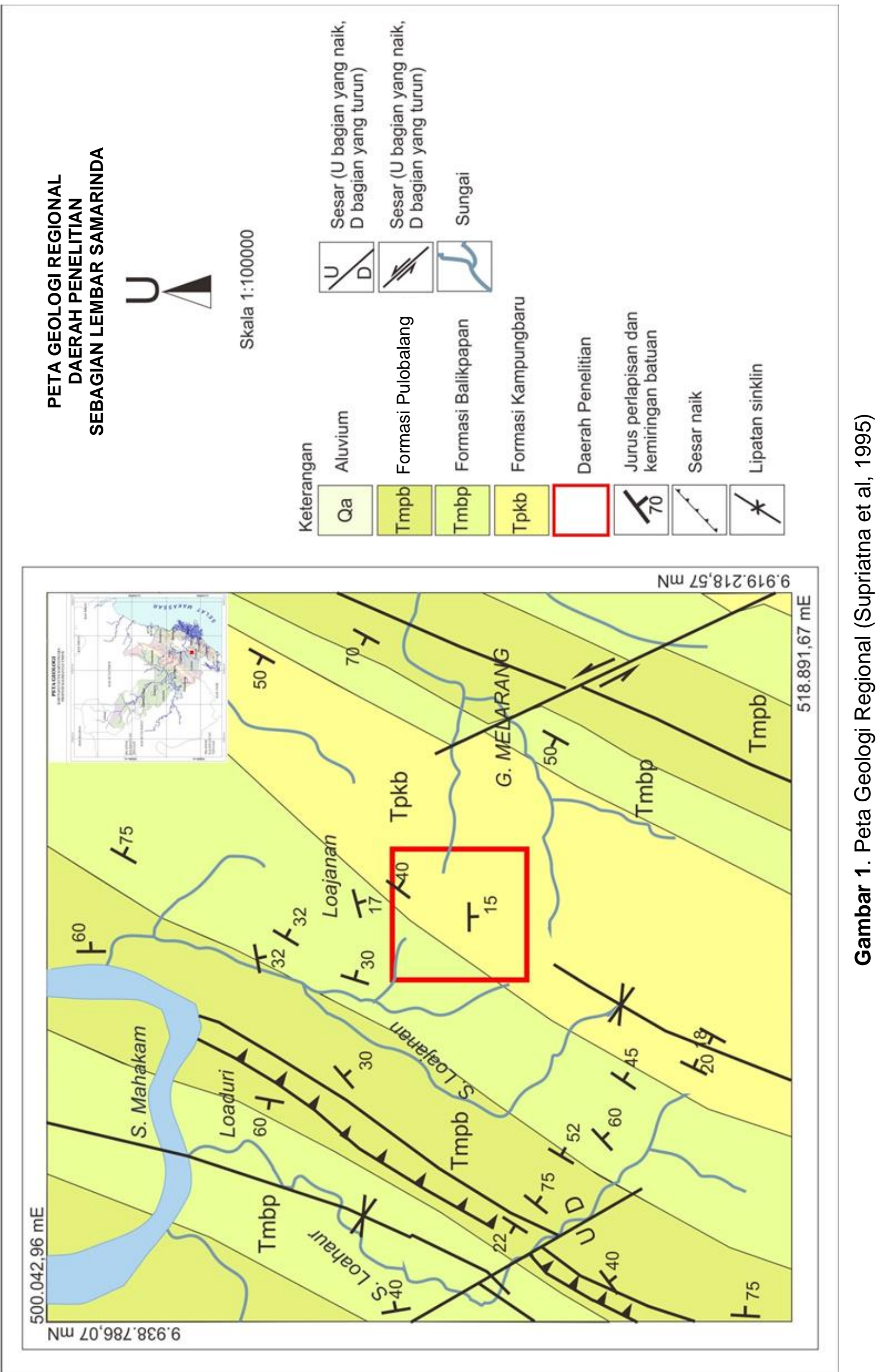


Formasi Balikpapan (Tmbp) terdiri dari perselingan batupasir dan batulempung dengan sisipan batulanau, batugamping dan batubara. Batupasir kuarsa berwarna putih kekuningan dengan tebal lapisan $1 \mathrm{~m}$ s.d. $3 \mathrm{~m}$ disisipi lapisan batubara dengan tebal $5 \mathrm{~cm}$ s.d. $10 \mathrm{~cm}$. batupasir gampingan berwarna coklat dengan struktur sedimen silang-siur, tebal lapisan $20 \mathrm{~cm}$ s.d. $40 \mathrm{~cm}$, disisipi lapisan tipis karbon. Sedangkan Formasi Kampungbaru (Tpkb) terdiri atas batupasir kuarsa dengan sisipan batulempung, serpih, lanau dan lignit dengan tebal $1 \mathrm{~m}$ s.d. $2 \mathrm{~m}$, pada umumnya lunak dan mudah hancur (Supriatna et al, 1995).

Berdasarkan pengamatan di lapangan, batubara di daerah penelitian memiliki ketebalan berkisar antara 4 meter hingga 8 meter. Terdapat 3 seam batubara yang ditambang di daerah penelitian.

Struktur geologi yang terdapat di sekitar daerah penelitian terdiri dari lipatan dengan sumbu berarah timurlaut-baratdaya dan sesar naik yang berada di sebelah baratlaut, serta sesar mendatar di sebelah tenggara daerah penelitian.

\section{Analisis kesetimbangan batas}

Analisis kesetimbangan batas (limit equilibrium analysis) merupakan metode yang mempertimbangkan kesetimbangan gaya sepanjang bidang gelincir (Gurocak, Alemdag, \& Zaman, 2008). Pada metode ini diasumsikan terdapat bidang gelincir yang potensial, dimana kondisi gaya (force) dan moment equilibrium ditentukan berada pada kondisi statis. Analisis ini membutuhkan informasi tentang kekuatan material (Swana, Muslim, \& Sophian, 2012). Perhitungan dilakukan dengan membagi tanah yang berada di atas bidang longsoran menjadi irisan-irisan, sehingga metode ini dikenal juga dengan nama metode irisan (slice method) (Liong \& Herman, 2012).

Dalam Liong \& Herman (2012), disebutkan bahwa metoda irisan yang pertama kali dipublikasikan oleh Fellenius merupakan cara yang paling sederhana dimana semua gaya antar irisan diabaikan dan hanya memperhitungkan keseimbangan momen. Kemudian Bishop mengembangkan cara yang lebih kompleks dengan memasukkan gaya yang bekerja di sekitar bidang irisan dan memperhitungkan keseimbangan momen. Perbedaan antar metoda terdapat pada Tabel 1 dan Tabel 2.

\section{Faktor Keamanan}

Dalam Hoek \& Bray (2005), dijelaskan bahwa untuk setiap jenis longsoran, dapat diasumsikan ke dalam Mohr-Couloumb dimana kekuatan material ditentukan berdasarkan kohesi (c) dan sudur gesek dalam $(\phi)$. Kestabilan lereng bisa dihitung berdasarkan rasio dari gaya penahan dan gaya pendorong, yang diistilahkan sebagai Safety-Factor (FS). Berikut persamaannya:

$$
\begin{aligned}
& F S=\frac{\text { Resisting Forces }}{\text { Driving Force }} \\
& F S=\frac{c A+W \cos \alpha p \operatorname{ptan} \phi}{W \sin \alpha \mathrm{p}} \\
& \text { Dimana } c=\text { kohesi } \\
& A=\text { luas area } \\
& W=\text { berat beban diatas bidang } \\
& \text { longsoran } \\
& \alpha=\text { sudut lereng } \\
& \phi= \text { sudut gesek dalam }
\end{aligned}
$$

Hal yang mempengaruhi nilai faktor keamanan (Safety-Factor/FS) diantaranya gravitasi, getaran dalam hal ini blasting maupun gempa yang berperan sebagai gaya pendorong, sedangkan kekuatan tanah itu sendiri berupa kohesi dan sudut geser dalam merupakan gaya penahan (Oscar, Muslim, Sulaksana, \& Hirnawan, 2016). Menurut Bowles (1984), apabila suatu lereng memiliki nilai $\mathrm{FS}>1,25$, yang berarti gaya penahan lebih besar daripada gaya penggerak, maka lereng tersebut berada dalam keadaan stabil. Tetapi, jika suatu lereng memiliki nilai $1,07<\mathrm{FS}<$ 1,25 , maka lereng tersebut berada dalam keadaan kritis. Dan bila suatu lereng memiliki nilai FS <1,07, maka lereng tersebut berada dalam keadaan tidak stabil dan rawan terjadi longsor (Tabel 3) 


\section{METODE}

Metode penelitian terdiri dari, studi literatur, pekerjaan lapangan, analisis laboratorium dan analisis studio. Tahap studi literatur berupa pengumpulan data sekunder mengenai daerah penelitian seperti peta lokasi daerah penelitian, kondisi geologi daerah penelitian dan data penelitian sebelumnya. Tahap pengerjaan lapangan berupa pengamatan terhadap karakteristik material, pengukuran geometri lereng pada disposal area serta pengambilan conto tanah tak terganggu dengan menggunakan pipa berukuran 3 inci (Gambar 2). Tahap analisis laboratorium meliputi uji kuat geser langsung batuan (direct shear) untuk memperoleh parameter kohesi dan sudut geser dalam tanah, serta pengujian sifat fisik tanah berupa uji bobot isi tanah, yang dilakukan di Laboratorium Geoteknik dan Geologi Teknik Universitas Padjadjaran. Tahap analisis studio berupa simulasi lereng dengan menggunakan aplikasi Slide versi 6 untuk mencari nilai nilai FS optimum yang diperkirakan masih aman menurut klasifikasi Bowles (1984).

Tabel 1. Perbandingan kesetimbangan momen dan kesetimbangan gaya yang bekerja pada analisis kesetimbangan batas (Liong \& Herman, 2012)

\begin{tabular}{lcc}
\hline Metode & Kesetimbangan momen & Kesetimbangan gaya \\
\hline Fellinius & Ya & Tidak \\
\hline Bishop's Simplified & Ya & Tidak \\
\hline Janbu's Simplified & Tidak & Ya \\
\hline Morgenstern Price & Ya & Ya \\
\hline Spencer & Ya & Ya \\
\hline Sarma & Ya & Ya \\
\hline
\end{tabular}

Tabel 2. Perbandingan gaya yang bekerja pada analisis kesetimbangan batas

\begin{tabular}{lccl} 
& \multicolumn{2}{c}{ (Liong \& Herman, 2012) } \\
\hline Metode & $\begin{array}{c}\text { Gaya Normal } \\
\text { Antar Irisan(E) }\end{array}$ & $\begin{array}{l}\text { Gaya Geser Antar } \\
\text { Irisan(X) }\end{array}$ & $\begin{array}{l}\text { Kemiringan Resultan X/E dan } \\
\text { hubungan antar X/E }\end{array}$ \\
\hline Fellinius & Tidak & Tidak & Tidak ada gaya antar irisan \\
\hline Bishop's Simplified & $\mathrm{Ya}$ & Tidak & Horizontal \\
\hline Janbu's Simplified & $\mathrm{Ya}$ & Tidak & Horizontal \\
\hline Morgenstern Price & $\mathrm{Ya}$ & $\mathrm{Ya}$ & Variabel ; user function \\
\hline Spencer & $\mathrm{Ya}$ & $\mathrm{Ya}$ & Konstan \\
\hline Sarma & $\mathrm{Ya}$ & $\mathrm{Ya}$ & $\mathrm{X}=\mathrm{C}+\mathrm{E}$ tan $\phi$ \\
\hline
\end{tabular}

Tabel 3. Klasifikasi faktor keamanan (Bowles, 1984)

\begin{tabular}{cc}
\hline $\mathrm{FS}$ & Kondisi \\
\hline $\mathrm{FS}<1,07$ & Labil (Longsor biasa terjadi) \\
\hline $1,07<\mathrm{FS}<1,25$ & Kritis (Longsor pernah terjadi) \\
\hline $\mathrm{FS}>1,25$ & Stabil (Longsor jarang terjadi) \\
\hline
\end{tabular}

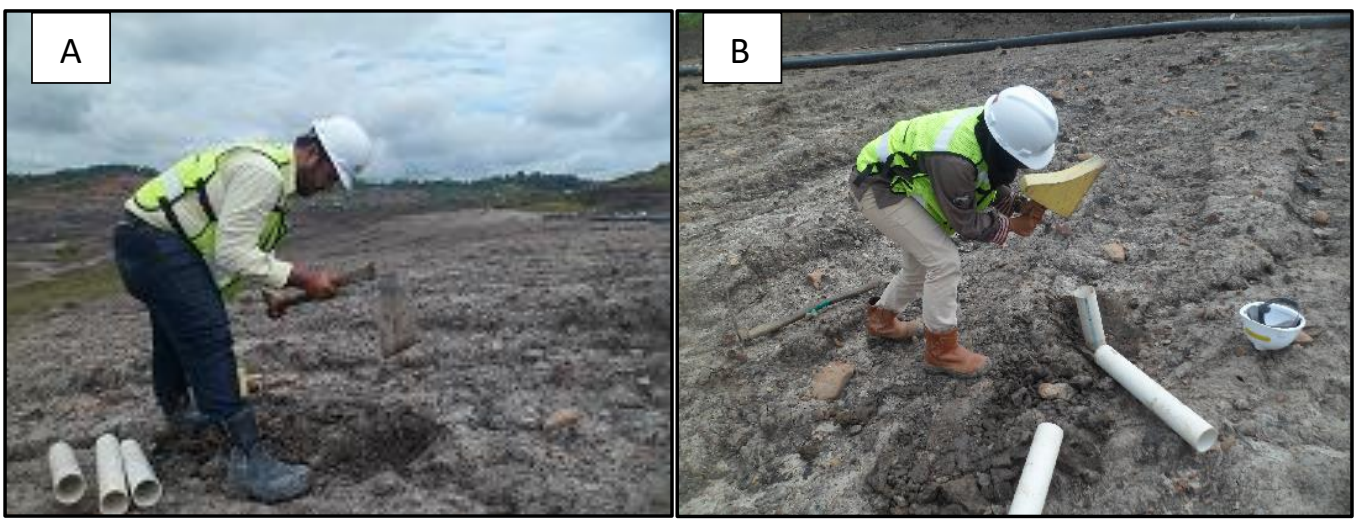

Gambar 2. (A) Penggalian atau pengerukan permukaan tanah. (B) Menancapkan pipa ke dalam tanah dengan cara dipukul untuk pengambilan conto tanah tidak terganggu 


\section{HASIL DAN PEMBAHASAN}

\section{Geologi Teknik Daerah Penelitian}

Berdasarkan hasil pemetaan geologi teknik, karakteristik persebaran tanah di daerah penelitian dibagi menjadi tiga satuan geologi teknik yang dikelompokkan berdasarkan sistem klasifikasi tanah USCS (Unified Soil Classification System) yaitu satuan tanah $\mathrm{CH}$ (High Plasticity Clay), satuan tanah CL (Low Plasticity Clay) untuk tanah original dan satuan tanah CLO (Low Plasticity Clay of Overburden Soil) untuk tanah timbunan (Gambar 3).

Satuan tanah $\mathrm{CH}$ memiliki karakteristik warna coklat, kohesif, lunak hingga agak lunak, plastisitas tinggi, ukuran lempung, tingkat pelapukan highly weathered hingga completely weathered zone, struktur homogen, terdapat material batubara dan batulempung. Satuan tanah CL pada tanah original memiliki karakteristik berwarna kuning kemerahan, kohesif, plastisitas rendah, kekuatan lunak hingga teguh, tingkat pelapukan completely weathered. Satuan tanah CL-O pada tanah timbunan memiliki karakteristik berwarna cokelat keabu-abuan hingga abu-abu, agak lunak, plastisitas rendah, tingkat pelapukan moderately weathered hingga highly weathered zone, bercampur dengan material batubara, batupasir.

Untuk mengetahui karakteristik fisik dan mekanika pada tanah disposal, maka dilakukan analisis laboratorium terhadap sampel tanah tak terganggu, yang selanjutnya data hasil analisis laboratorium tersebut akan digunakan untuk analisis kestabilan lereng tanah. Pengujian sifat fisik tanah yang dilakukan adalah uji berat volume yang bertujuan untuk mengetahui bobot isi tanah atau massa tanah per volume tertentu. Kemudian uji sifat mekanika tanah yang dilakukan adalah uji kuat geser langsung (direct shear test) untuk memperoleh nilai kohesi dan sudut geser dalam tanah.

Berdasarkan hasil pengujian pada tiga conto tanah pada disposal area, serta satu conto tanah in situ diperoleh nilai bobot isi tanah, kohesi dan juga sudut geser dalam tanah dari masing-masing conto (Tabel 4).

Tabel 4. Nilai kohesi, sudut geser dalam dan bobot isi tanah dari conto tanah tak terganggu

\begin{tabular}{lrrrrr}
\hline $\begin{array}{l}\text { Kode } \\
\text { conto }\end{array}$ & $\begin{array}{c}\mathrm{C} \\
\left(\mathrm{kg} / \mathrm{cm}^{2}\right)\end{array}$ & $\phi(0)$ & $\begin{array}{c}\gamma \text { wet } \\
\left(\mathrm{gr} / \mathrm{cm}^{3}\right)\end{array}$ & $\omega(\%)$ & $\begin{array}{c}\gamma \text { dry } \\
\left(\mathrm{gr} / \mathrm{cm}^{3}\right)\end{array}$ \\
\hline GT01 & 1,34 & 23,3 & 2,086 & & 1,767 \\
\hline SO5 & 0,29 & 14 & 2,07 & 19,86 & 1,525 \\
\hline SO6 & 0,31 & 14 & 1,902 & 24,32 & 1,524 \\
\hline SO7 & 0,38 & 14 & 1,89 & 26,33 & 1,430 \\
\hline
\end{tabular}

\section{Simulasi Kestabilan Lereng}

Disposal area berada di sebelah utara pit. Material pada disposal area ini berupa material overburden atau material timbunan dari pit berupa material berukuran lempung, lanau, dan pasir. Berdasarkan pengamatan lapangan, terdapat beberapa lokasi atau titik longsor yang berada pada lereng disposal area di daerah penelitian seperti pada Gambar 4 dan Gambar 5.

Untuk dapat mengetahui nilai FS pada lereng disposal, dibuat tiga penampang yang berarah baratlaut-tenggara (Gambar 3). Perhitungan nilai FS dilakukan menggunakan analisis kesetimbangan batas, dimana pada analisis ini dibutuhkan parameter nilai kohesi, sudut gesek dalam dan bobot isi tanah. Dari penampang tersebut memiliki nilai FS berkisar antara 1,186 s.d. 1,746 (Tabel 5).

Tabel 5. Nilai FS lereng aktual

\begin{tabular}{crrrr}
\hline Penampang & $\begin{array}{c}\text { Tinggi } \\
\text { lereng } \\
(\mathrm{m})\end{array}$ & $\begin{array}{c}\text { Tebal } \\
\text { timbunan } \\
(\mathrm{m})\end{array}$ & $\begin{array}{c}\text { Sudut } \\
\text { lereng } \\
\left({ }^{\circ}\right)\end{array}$ & FS \\
\hline 1 & 82 & 20 & 8 & 1,186 \\
\hline 2 & 71,8 & 19 & 11 & 1,21 \\
\hline 3 & 72 & 9 & 10 & 1,746 \\
\hline
\end{tabular}

Pada disposal ini, nilai FS minimum yang disarankan adalah 1,25 (Bowles, 1984), sehingga kondisi lereng disposal (overall slope) aktual saat ini masih belum aman karena dari ketiga sayatan, dua sayatan memiliki nilai FS kurang dari 1,25. Untuk mendapatkan nilai FS yang aman dengan sudut lereng optimum, dilakukan simulasi lereng terhadap overall slope dalam 
beberapa kondisi ketebalan timbunan dan variasi sudut (Tabel 6 dan Gambar 7).

Pada kolom yang diberi warna merah merupakan nilai FS pada kondisi lereng labil atau kritis, dengan nilai FS kurang dari 1,25 .

Tabel 6. Nilai FS hasil simulasi lereng

\begin{tabular}{crrrr}
\hline \multirow{2}{*}{$\begin{array}{c}\text { Tebal } \\
\text { timbunan } \\
(m)\end{array}$} & \multicolumn{3}{c}{$\begin{array}{c}\text { Nilai FS Pada Kondisi Simulasi } \\
\text { Desain Lereng }\end{array}$} \\
\cline { 2 - 5 } & \multicolumn{2}{c}{ Slope $=9$} & \multicolumn{2}{c}{ Slope=12 } \\
\cline { 2 - 5 } & Jenuh & $\begin{array}{c}\text { Tak } \\
\text { jenuh }\end{array}$ & Jenuh & Tak jenuh \\
\hline 15 & 1,35 & 2,165 & 0,937 & 1,552 \\
\hline 20 & 1,174 & 1,552 & 0,809 & 1,440 \\
\hline 25 & 1,066 & 1,807 & 0,817 & 1,285 \\
\hline 30 & 1,026 & 1,76 & 0,757 & 1,304 \\
\hline
\end{tabular}

Hasil analisis studio menggunakan aplikasi Slide Versi 6, pada penampang 1 diperoleh nilai FS lereng disposal 1,186 (Tabel 5 dan Gambar 6).

Seperti yang terdapat pada Tabel 5, lereng berada dalam kondisi aman dengan maksimum tinggi timbunan 15 meter dengan kemiringan lereng keseluruhan adalah $9^{\circ}$ dengan kondisi jenuh air, sementara pada kondisi lereng tak jenuh, lereng berada dalam kondisi masih aman hingga tinggi timbunan mencapai 30 meter dengan kemiringan lereng keseluruhan $12^{\circ}$. Kondisi pada simulasi ini, lereng digambarkan tidak memiliki undakan, sehingga jika lereng dibuat berundak, maka nilai FS dapat lebih besar.

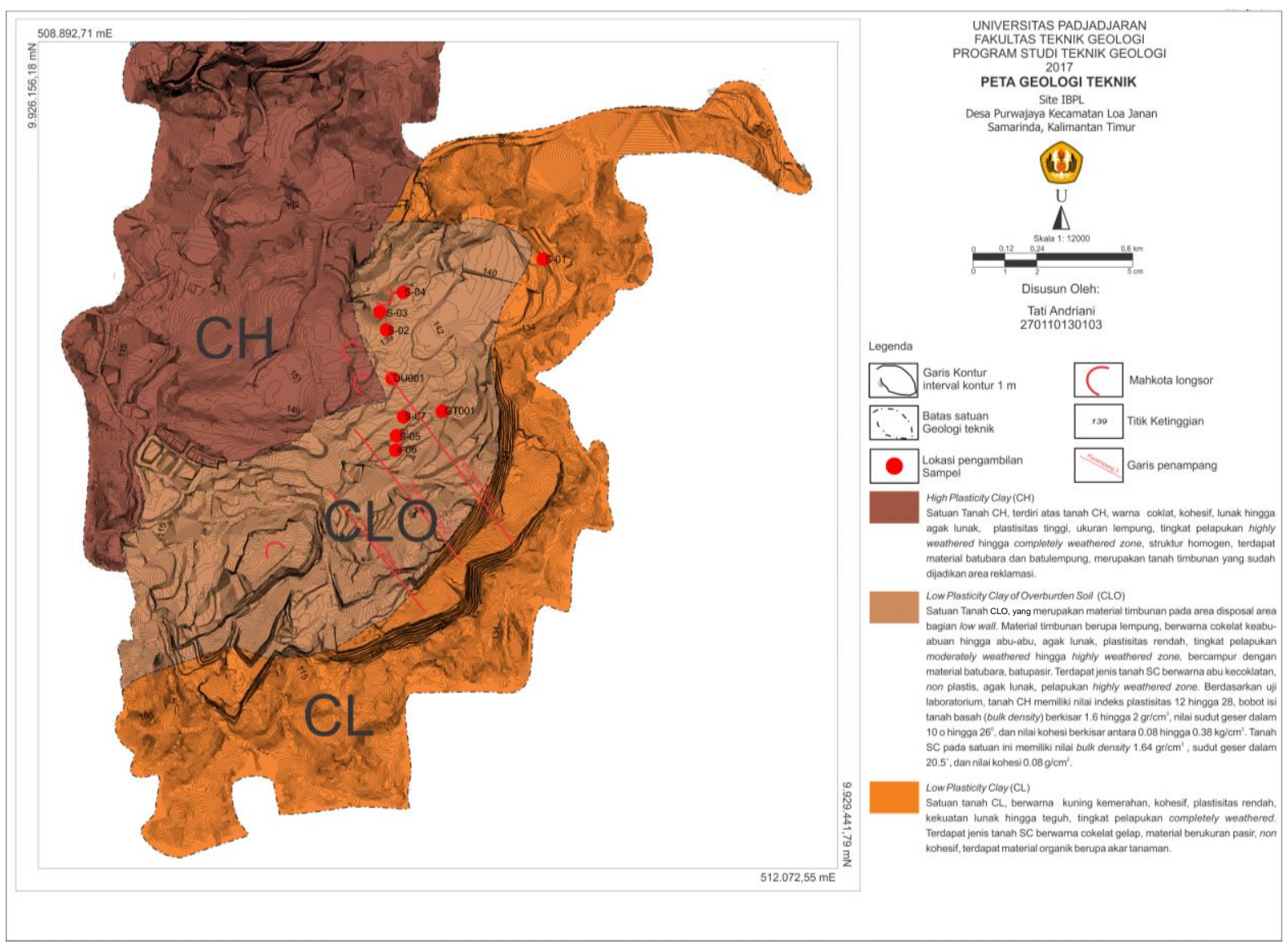

Gambar 3. Peta geologi teknik daerah penelitian 


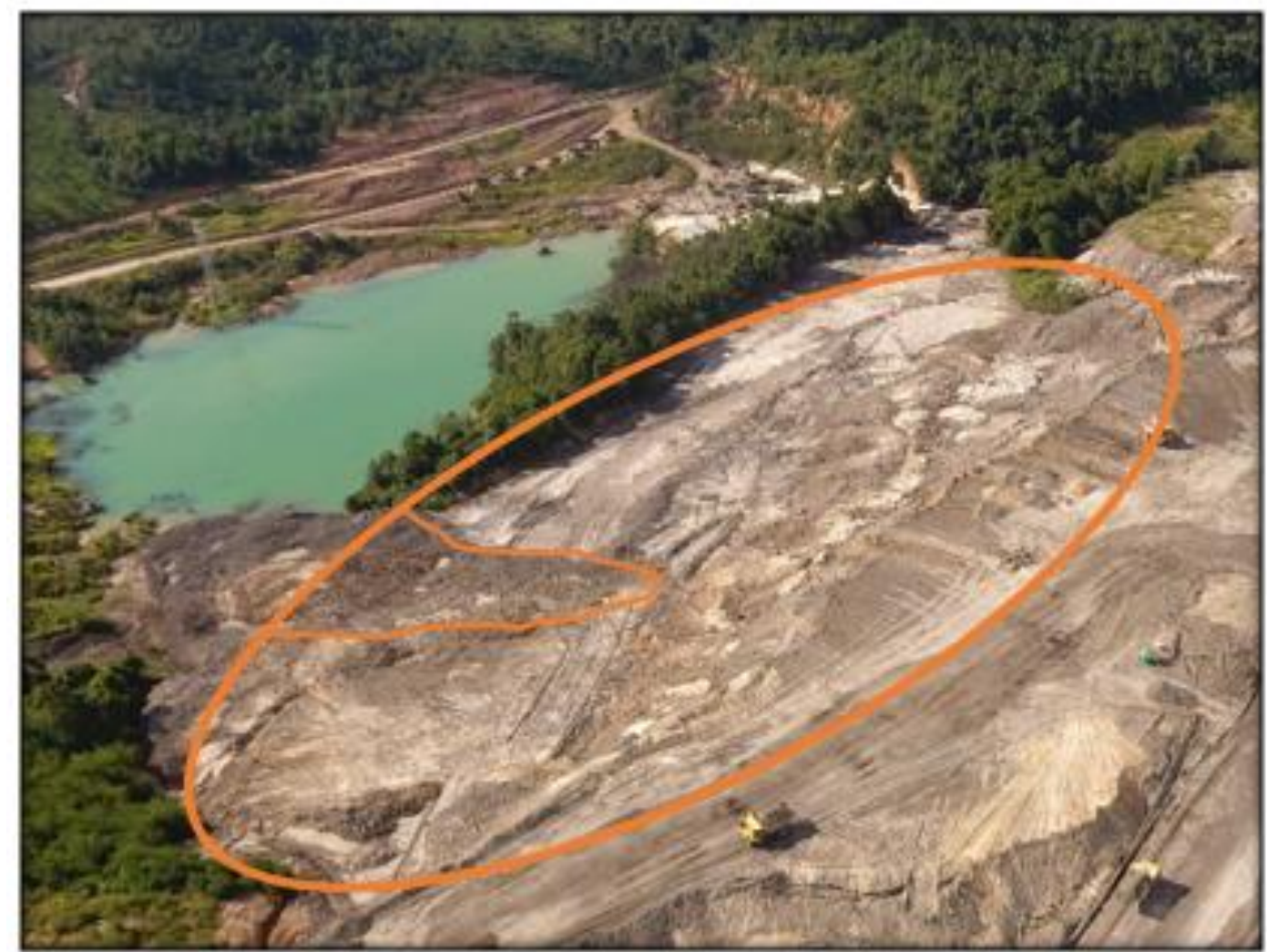

Gambar 4. Kondisi area disposal daerah penelitian, bagian barat yang ditandai merupakan longsoran pada disposal

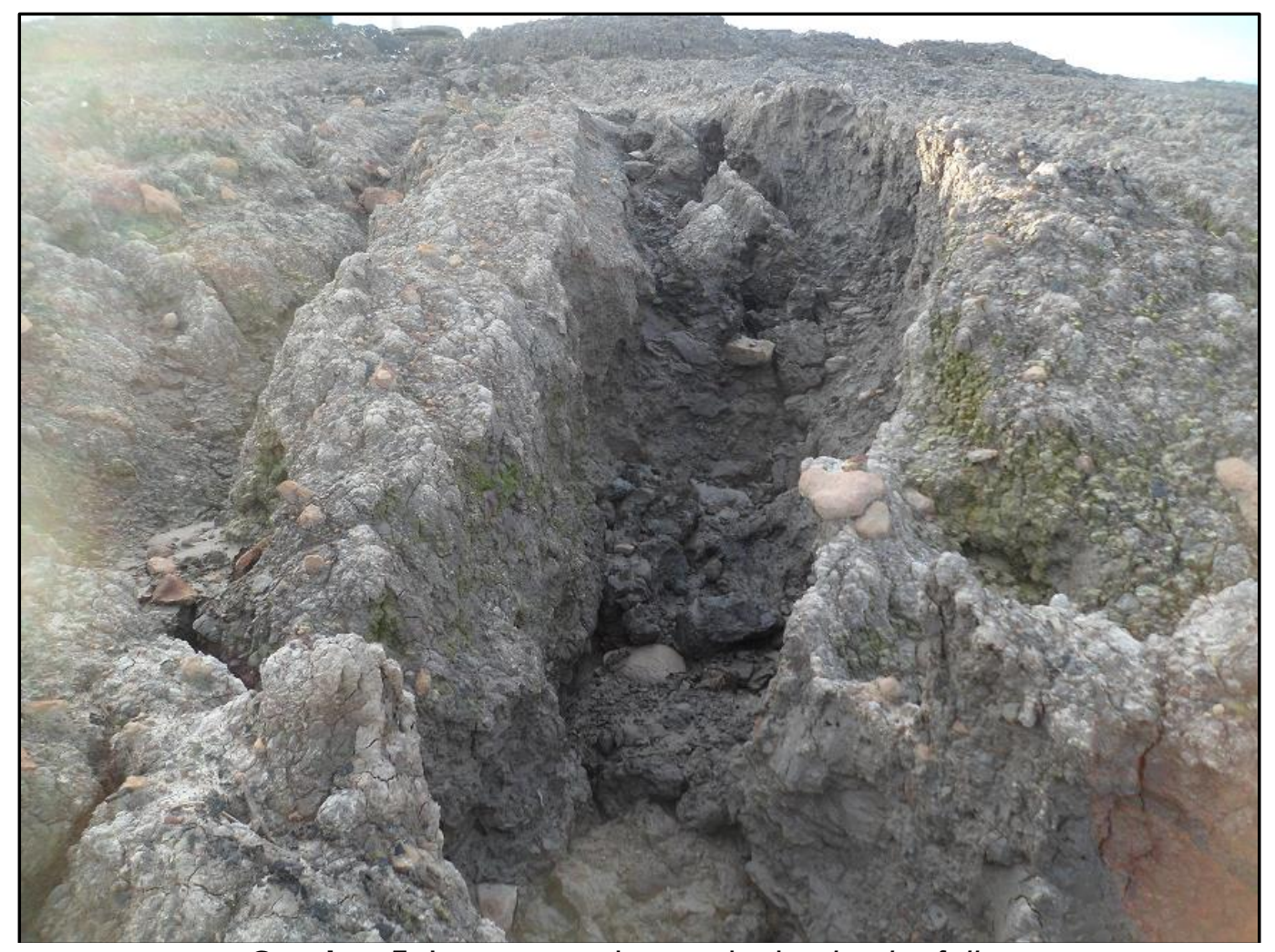

Gambar 5. Longsoran dengan jenis circular failure

pada disposal area di daerah penelitian 


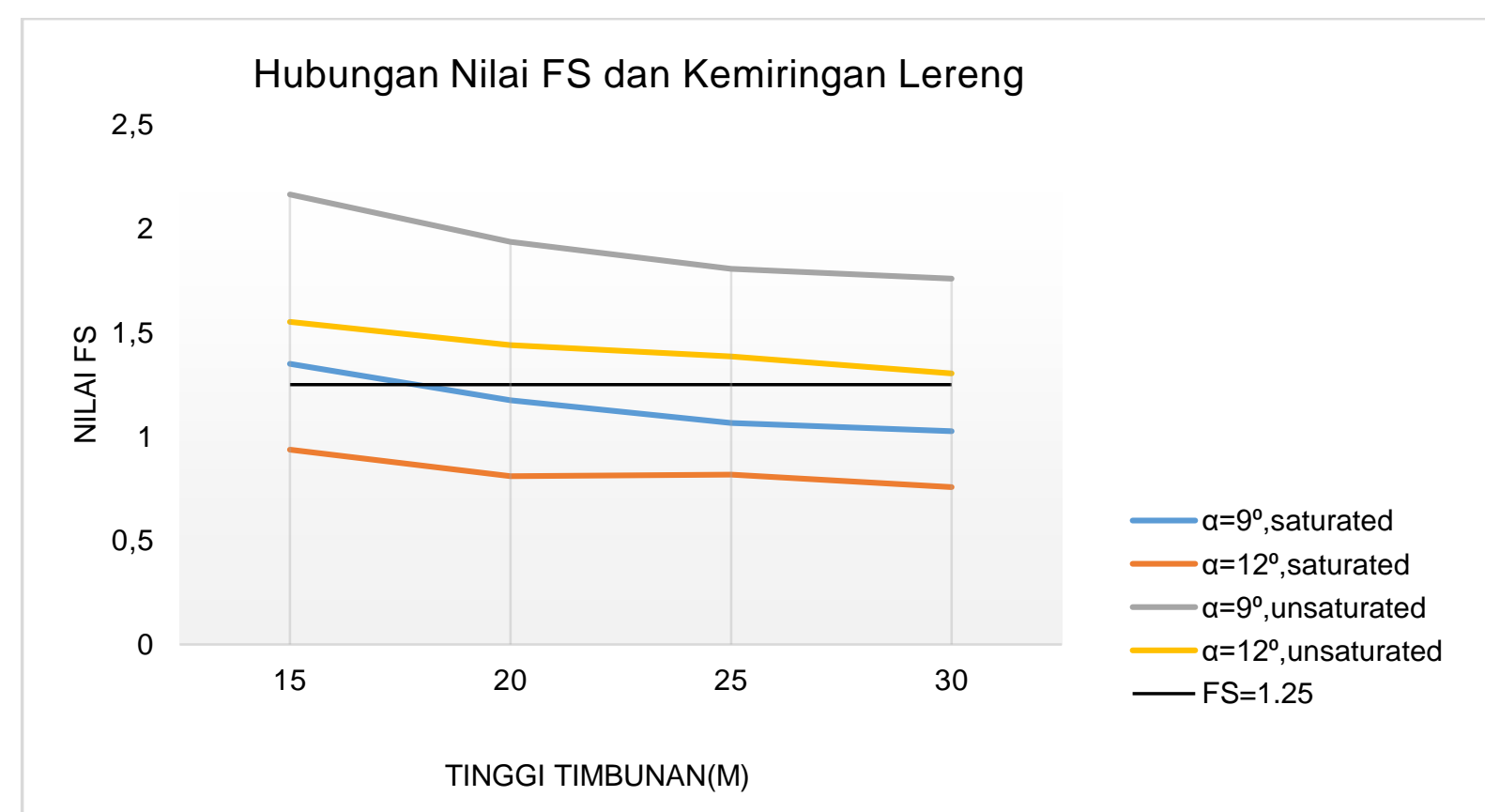

Gambar 6. Hubungan nilai FS dengan kemiringan lereng pada simulasi lereng keseluruhan

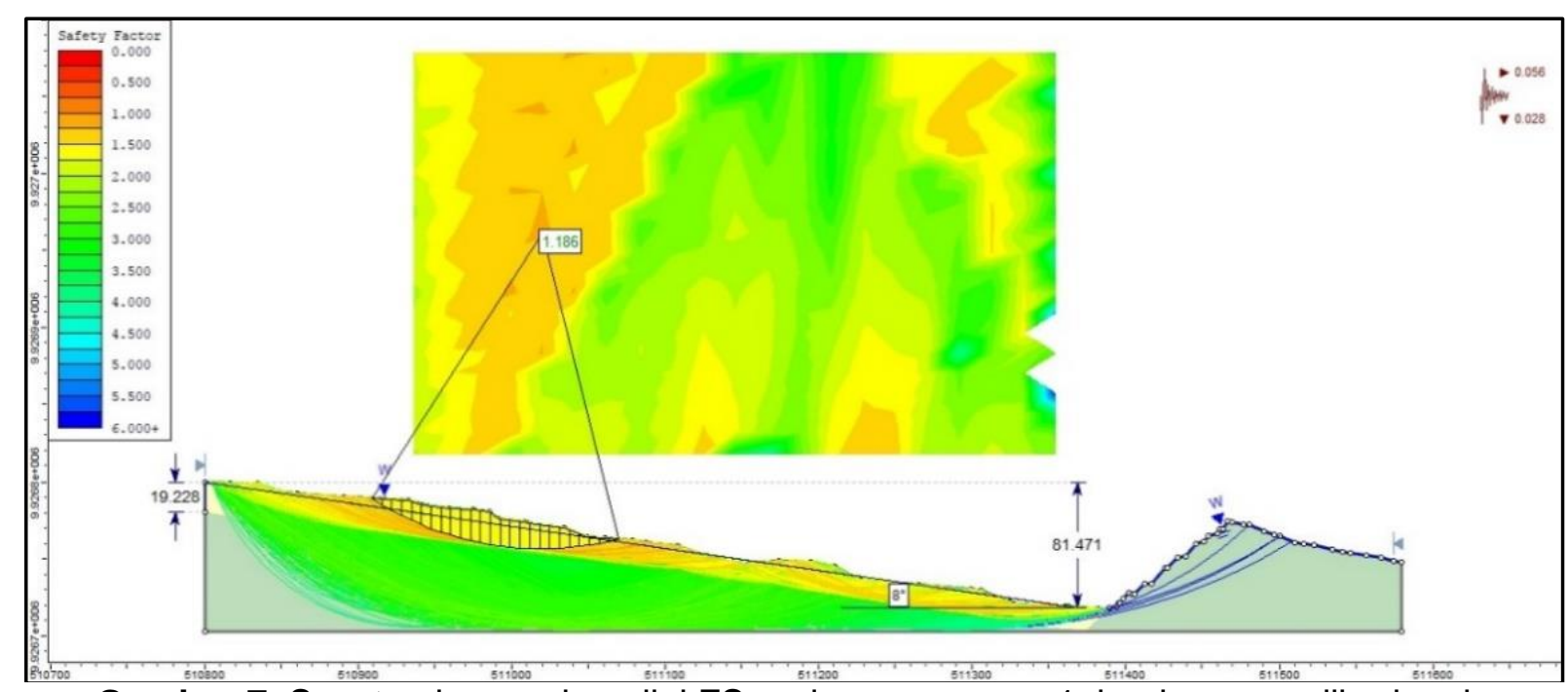

Gambar 7. Sayatan lereng dan nilai FS pada penampang 1, bagian yang diberi arsir merupakan bidang gelincir longsoran

Pada Gambar 8, dapat dilihat bahwa untuk kondisi jenuh, lereng tunggal dapat stabil atau memiliki nilai FS lebih dari 1,25 hingga pada tinggi lereng $7 \mathrm{~m}$ dengan sudut lereng $31^{\circ}$, artinya untuk ketinggian lereng 5 meter, lereng masih dapat stabil pada setiap variasi sudut yang disimulasikan. Sedangkan untuk tinggi lereng 10 meter dan 15 meter, lereng berada dalam kondisi labil dengan nilai FS kurang dari 1,25.

Pada Gambar 9 merupakan contoh desain lereng yang disarankan pada disposal area dengan geometri lereng tunggal, tinggi lereng $7 \mathrm{~m}$, sudut lereng $30^{\circ}$. Sedangkan untuk lereng keseluruhan, tebal timbunan $20 \mathrm{~m}$ dan sudut lereng $9^{\circ}$ dengan nilai $\mathrm{FS}$ 1,301 . 


\section{Hubungan Nilai FS dengan Kemiringan Lereng (Saturated)}

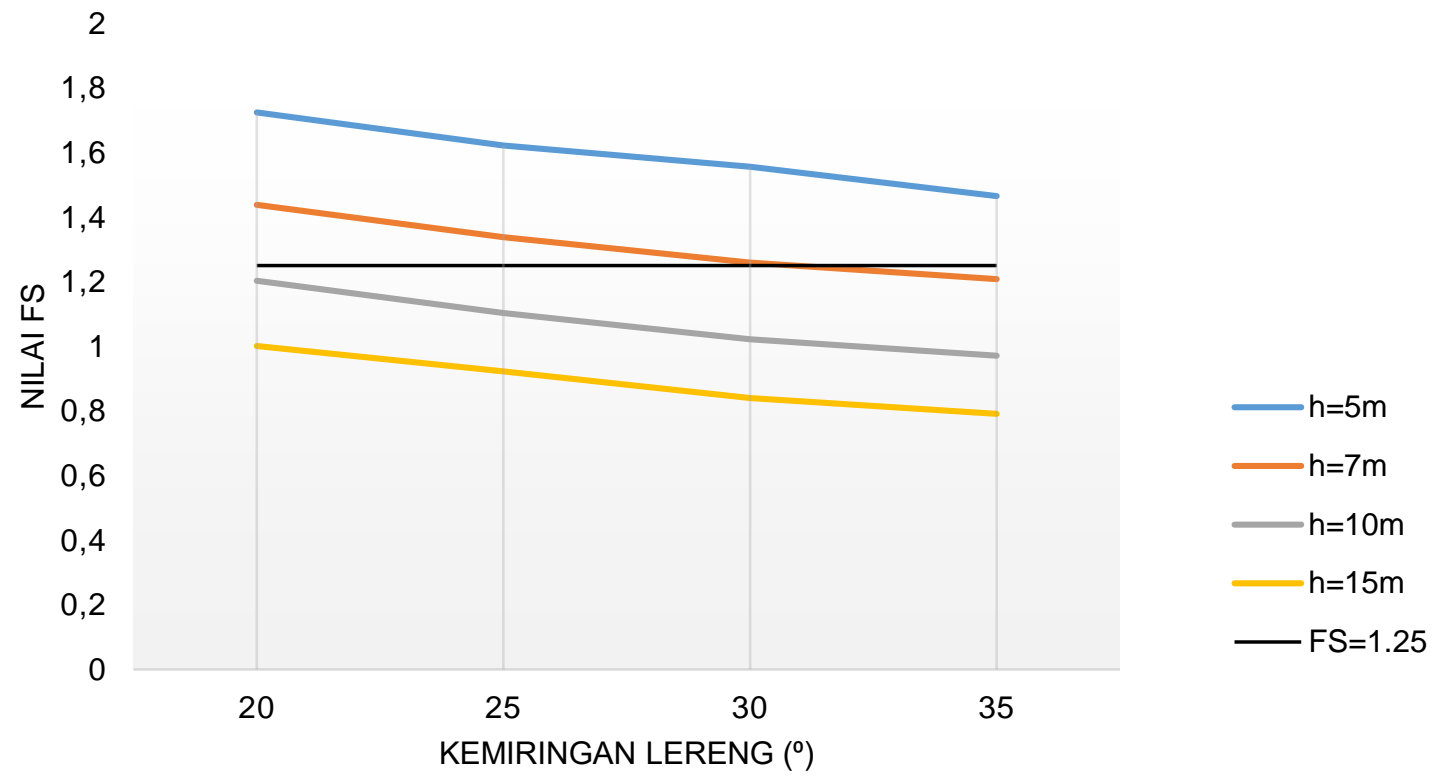

Gambar 8. Hubungan nilai FS dengan kemiringan lereng saturated pada simulasi lereng tunggal

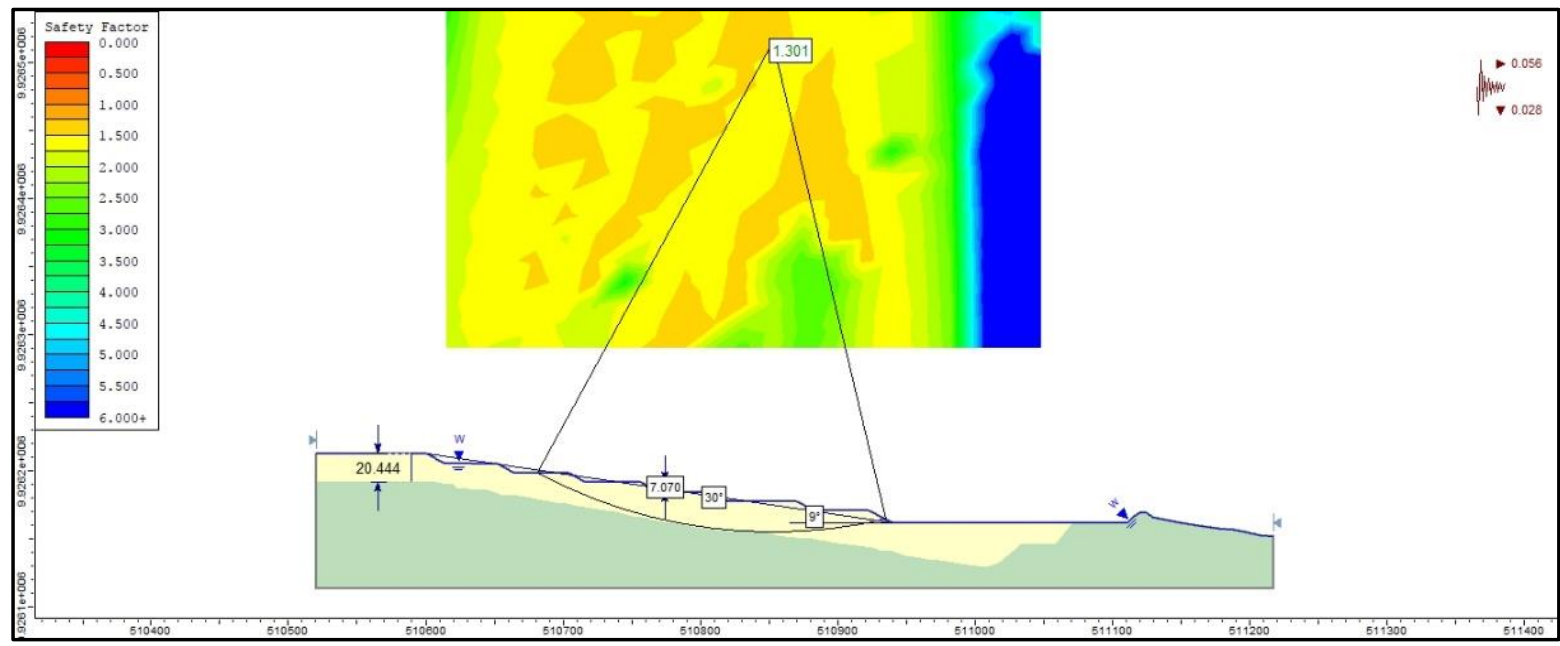

Gambar 9. Contoh simulasi lereng yang disarankan dengan tinggi timbunan $20 \mathrm{~m}$, sudut lereng keseluruhan $9^{\circ}$ dan sudut lereng tunggal $30^{\circ}$

\section{KESIMPULAN}

Berdasarkan perhitungan nilai FS aktual lereng disposal saat ini masih berada dalam kondisi belum stabil dengan nilai FS 1,186 untuk sayatan 1 ; FS 1,21 untuk sayatan 2 dan FS 1,756 untuk sayatan 3 sehingga perlu adanya perbaikan geometri lereng. Berdasarkan hasil simulasi terhadap variasi tinggi dan sudut kemiringan lereng, didapatkan geometri lereng optimum dengan nilai FS 1,301 yaitu dengan tinggi timbunan 20 meter dan sudut lereng $9^{\circ}$ untuk lereng keseluruhan, serta tinggi lereng 7 meter dengan sudut lereng maksimum $30^{\circ}$ untuk lereng tunggal. 


\section{SARAN}

Parameter tinggi lereng serta sudut kemiringan ini dipengaruhi oleh kondisi materialnya, material disposal bersifat lunak dengan tingkat pelapukan yang tinggi, dan juga nilai kekuatan material berkurang akibat penggaruan, sehingga geometri lereng yang dapat dibuat agar kondisi lereng tetap aman ialah dengan tinggi lereng tidak terlalu besar dan kemiringan lereng tidak terlalu curam. Parameter yang dapat digunakan adalah tinggi lereng keseluruhan 20 meter dengan sudut lereng keseluruhan $9^{\circ}$, serta tingi lereng tunggal 7 meter dengan sudut kemiringan lereng $30^{\circ}$.

\section{UCAPAN TERIMA KASIH}

Penulis mengucapkan terimakasih kepada pimpinan PT. Kalimantan Prima Persada (KPP) yang telah memberikan kesempatan kepada penulis untuk pengambilan data di salah satu site KPP.

\section{DAFTAR PUSTAKA}

Behera, P. Ku., Kripamoy, S., Singh, A. K., Verma, A. K., \& Singh, T. N. (2016). Dump Slope Stability Analysis - A Case Study, 88(December), 725-735.

Bowles, J. E. (1984). Sifat-sifat Fisis dan Geoteknis Tanah (Mekanika Tanah). Jakarta: Erlangga.

Gurocak, Z., Alemdag, S., \& Zaman, M. M. (2008). Rock slope stability and excavatability assessment of rocks at the Kapikaya dam site , Turkey, 96, 17-27. https://doi.org/10.1016/j.enggeo.2007. 08.005 .
Hoek, E., \& Bray, J. (2005). Rock Slope Engineering Civil and Mining (4th ed.). New York: Press, Spon.

Kristyanto, T. H. W., Muslim, D., \& Zakaria, Z. (2015). Determination of Dumping Area Based on Engineering Geological Study. In ACEAIT-3662 (pp. 638-644).

Liong, G. T., \& Herman, D. J. (2012). Analisa Stabilitas Lereng Limit Equilibrium vs Finite Element Method. In HATTI-PIT-XVI. Jakarta.

Oscar, A. W., Muslim, D., Sulaksana, N., \& Hirnawan, F. (2016). Response of Stable Overall Slope Geometry of Open Pit Coal Mine in Warukin Formation to Dewatering and Peak Ground Seismic in South Kalimantan, Indonesia. Buletin Sumber Daya Geologi, 11(1), 55-72.

Prasetyo, S. I., Hariyanto, \& Cahyadi, T. A. (2011). Studi Kasus Analisa Kestabilan Lereng Disposal di Daerah karuh, Kecamatan Kintap, kabupaten Tanah laut, kalimantan selatan. In Seminar Nasional ke 6 Tahun 2011: Rekayasa Teknologi Industri dan Informasi (pp. 381-387). Yogyakarta: UPN Veteran Yogyakarta.

Supriatna, Sukardi, \& Rustandi. (1995). Peta Geologi Lembar Samarinda. Pusat Penelitian dan Pengembangan Geologi.

Swana, G. W., Muslim, D., \& Sophian, I. (2012). Desain Lereng Final Dengan Metode Rmr, Smr dan Analisis Kestabilan Lereng: pada Tambang Batubara Terbuka, di Kabupaten Tanah Laut, Provinsi Kalimantan Selatan. Buletin Sumber Daya Geologi, 7, 92-108.

\begin{tabular}{|ll|}
\hline Diterima & $:$ 25 September 2017 \\
Direvisi & $: 06$ Oktober 2017 \\
Disetujui & $: 29$ November 2017
\end{tabular}

